\title{
Role of Gas6 receptors in platelet signaling during thrombus stabilization and implications for antithrombotic therapy
}

\author{
Anne Angelillo-Scherrer, ${ }^{1}$ Laurent Burnier, ${ }^{1}$ Nathalie Flores, ${ }^{1}$ Pierre Savi, ${ }^{2}$ Maria DeMol, ${ }^{3}$ \\ Paul Schaeffer, ${ }^{2}$ Jean-Marc Herbert, ${ }^{2}$ Greg Lemke, ${ }^{4}$ Stephen P. Goff, ${ }^{5}$ Glenn K. Matsushima, ${ }^{6}$ \\ H. Shelton Earp, ${ }^{7}$ Christian Vesin, ${ }^{8}$ Marc F. Hoylaerts, ${ }^{3}$ Stéphane Plaisance, ${ }^{3}$ Désiré Collen, ${ }^{3}$ \\ Edward M. Conway, ${ }^{3}$ Bernhard Wehrle-Haller, ${ }^{8}$ and Peter Carmeliet ${ }^{3}$
}

${ }^{1}$ Division of Angiology and Hemostasis, Department of Internal Medicine, Faculty of Medicine and University Hospitals of Geneva, Geneva, Switzerland. 2Department of Cardiovascular Research, Sanofi-Synthélabo Recherche, Toulouse, France. ${ }^{3}$ Center for Transgene Technology and Gene Therapy, Flanders Interuniversity Institute for Biotechnology, and Center for Molecular and Vascular Biology, University of Leuven, Leuven, Belgium. ${ }^{4}$ The Salk Institute for Biological Studies, San Diego, California, USA. ${ }^{5}$ Department of Biochemistry and Molecular Biophysics, Columbia University, New York, New York, USA. ${ }^{6}$ University of North Carolina Neuroscience Center, and 7 Lineberger Comprehensive Cancer Center, University of North Carolina at Chapel Hill, Chapel Hill, North Carolina, USA. ${ }^{8}$ Department of Cellular Physiology and Metabolism, University of Geneva Medical School, Geneva, Switzerland.

\begin{abstract}
Mechanisms regulating thrombus stabilization remain largely unknown. Here, we report that loss of any 1 of the Gas6 receptors (Gas6-Rs), i.e., Tyro3, Axl, or Mer, or delivery of a soluble extracellular domain of Axl that traps Gas6 protects mice against life-threatening thrombosis. Loss of a Gas6-R does not prevent initial platelet aggregation but impairs subsequent stabilization of platelet aggregates, at least in part by reducing "outsidein" signaling and platelet granule secretion. Gas6, through its receptors, activates PI3K and Akt and stimulates tyrosine phosphorylation of the $\beta_{3}$ integrin, thereby amplifying outside-in signaling via $\alpha_{\mathrm{IIb}} \beta_{3}$. Blocking the Gas6-R- $\alpha_{\mathrm{II}} \beta_{3}$ integrin cross-talk might be a novel approach to the reduction of thrombosis.
\end{abstract}

\section{Introduction}

Formation of a platelet plug initiates hemostasis at sites of vascular injury and triggers pathological thrombosis in ischemic tissue disease. After initial formation of a single platelet monolayer, additional platelets are recruited into the growing hemostatic plug. Without further stabilization, platelet plugs prematurely disaggregate. While platelet plug instability may precipitate rebleeding at sites of vascular injury, inhibition of platelet plug stabilization may be therapeutically attractive to prevent pathological thrombosis. Indeed, agents inhibiting the formation of stable platelet plugs, but leaving behind an intact platelet coverage, might block thrombosis, possibly without eliciting major adverse bleeding effects. The availability of such compounds would be desirable, as currently available antithrombotic agents often cause a bleeding diathesis.

The molecular mechanisms controlling perpetuation of the platelet plug are incompletely characterized. The $\alpha_{\mathrm{IIb}} \beta_{3}$ integrin plays a central role in platelet aggregation. In the initial phase, activation of platelets by $\mathrm{ADP}$, thromboxane $\mathrm{A}_{2}$ (TXA $)$, and thrombin signals "inside-out" via $\alpha_{\mathrm{IIb}} \beta_{3}$, thereby increasing its ligand binding and activation (1). In the perpetuation phase, the activated $\alpha_{\mathrm{II}} \beta_{3}$ transmits critical "outside-in" signals, which commits the platelets to activation, irreversible platelet aggregation, and clot retraction (1). A critical signaling event includes the phosphorylation of tyrosine residues in the cytoplasmic domain of the $\beta_{3}$ integrin (2-4). Additional outside-in signaling molecules include the Eph kinases and ephrins, and CD40 ligand $(5,6)$.

Nonstandard abbreviations used: Gas6-R, Gas6 receptor; G/l, giga/liter; hAxl-EC-Fc, soluble Axl extracellular domain; PAR, protease-activated receptor; PPP, platelet-poor plasma; PRP, platelet-rich plasma; TXA 2 , thromboxane $\mathrm{A}_{2}$. Conflict of interest: The authors have declared that no conflict of interest exists. Citation for this article: J. Clin. Invest. 115:237-246 (2005). doi:10.1172/JCI200522079.
We recently reported that Gas6 enhances the formation of stable platelet macroaggregates in response to various agonists (7). Gas6 binds to the receptor tyrosine kinases Tyro3, Axl, and Mer via its carboxyterminal globular domain (8-10). Each of the Gas6 receptors (Gas6-Rs) has an extracellular ligand-binding domain and a cytoplasmic tyrosine kinase domain, the activity of which is enhanced by Gas6 (9, 11-17). This then leads to further intracellular signaling, including activation of the PI3K and Akt pathways (18-20). The Gas6-R-mediated signaling cascades in platelets remain unknown. Gas $6^{-/-}$mice are protected against thrombosis but do not suffer from bleeding (7). Mice with a triple deficiency of Tyro3, Axl, and Mer have not been reported to exhibit abnormal hemostasis under baseline conditions (21), but their response in pathological conditions was not evaluated.

In this study, we determined that Gas6, through its receptors, activates PI3K and Akt and stimulates tyrosine phosphorylation of the $\beta_{3}$ integrin, thereby amplifying outside-in signaling via $\alpha_{\mathrm{II}} \beta_{3}$. Furthermore, we established that a "Gas6 trap" prevents pathological thrombosis, which indicates that this novel cross-talk between the Gas6-Rs and $\alpha_{\mathrm{II}} \beta_{3}$ integrin may constitute a novel target for antithrombotic therapies.

\section{Results}

Loss of a Gas6-R causes rebleeding and protection against thrombosis. Mice lacking any 1 of the Gas6-Rs, i.e., Tyro3-/-, $\mathrm{Axl}^{-/-}$, or $\mathrm{Mer}^{-/-}$mice, did not suffer spontaneous bleeding or thrombosis under baseline conditions. We used 2 bleeding models to investigate the effects of loss of any 1 of the Gas6-Rs on hemostasis. In the first model, we determined the time to cessation of bleeding. When bleeding did not recur within 60 seconds of cessation, bleeding was considered to be arrested. All genotypes had normal bleeding times after tail clipping: $290 \pm 56$ seconds for WT mice, $300 \pm 32$ 


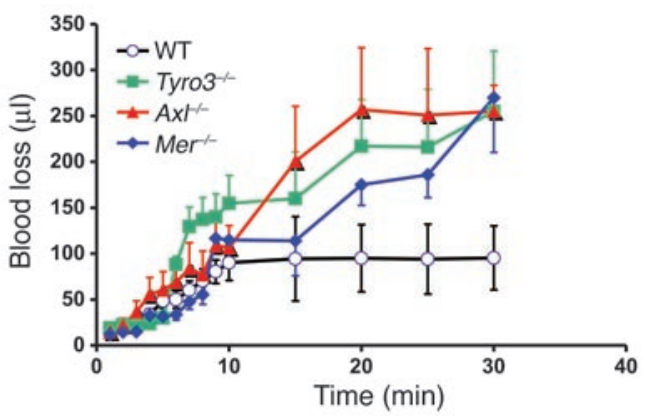

\section{Figure 1}

Effect of the lack of Tyro3, Axl, or Mer on hemostasis. After 2-mm tailtip transection, the cut end of the tail was immersed in saline at $37^{\circ} \mathrm{C}$. Aliquots of saline solution containing blood were sampled every minute for 10 minutes and then every 5 minutes until 30 minutes. The amount of blood loss was determined by measurement of the hemoglobin content of the aliquots of blood collected in saline (mean \pm SEM, $n=10$ ). In WT mice, blood loss reached a plateau within 10 minutes, indicating cessation of bleeding. In contrast, Tyro3 ${ }^{-/}, \mathrm{AxI}^{-/-}$, and $\mathrm{Mer}^{-/-}$mice had a tendency to repetitively rebleed after transient hemostasis.

seconds for Tyro3 $^{-/-}$mice, $220 \pm 17$ seconds for $A x^{-/-}$mice, and $200 \pm 36$ seconds for $\mathrm{Mer}^{-/-}$mice (mean \pm SEM, $n=10, P=\mathrm{NS}$ ). As the first bleeding model is not suitable to detect rebleeding after initial hemostasis, we used a second model where the amount of blood loss was estimated every minute for 10 minutes and, thereafter, every 5 minutes until 30 minutes. In WT mice, blood loss increased progressively to reach a plateau within 10 minutes, after which bleeding stopped completely. In contrast, Tyro3 ${ }^{-/-}, \mathrm{Axl}^{-{ }^{-}}$, or $\mathrm{Mer}^{-/-}$mice had a tendency to repetitively rebleed after transient hemostasis, as shown by the stepwise increase in blood loss (Figure 1). Consequently, Gas6-R-deficient mice lost more blood during 30 minutes after tail clipping than WT mice $(95 \pm 35 \mu \mathrm{l}$ in WT mice versus $260 \pm 66 \mu \mathrm{l}$ in Tyro $^{-/-}$mice, $260 \pm 28 \mu \mathrm{l}$ in $A \times l^{-/-}$mice, and $270 \pm 60 \mu \mathrm{l}$ in $\mathrm{Mer}^{-/-}$mice; $\left.n=10, P<0.05\right)$. Similar results were obtained in $\mathrm{Gas}^{-/-}$mice (data not shown).

Two thrombosis models were used to determine the role of Tyro3, Axl, or Mer in pathological thrombosis. In the first model, thrombosis was induced by ligation of the inferior vena cava followed by i.v. injection of tissue thromboplastin. Stasis-induced venous thrombosis results from both coagulation and platelet activation (22). Compared with WT mice, thrombi in Tyro3 ${ }^{-/-}, \mathrm{Axl}^{-/-}$, or $\mathrm{Mer}^{-/-}$mice were on average reduced by more than $90 \%(n=10, P<0.005$; Figure $2 \mathrm{~A})$. In the second model, platelet-dependent thromboembolism was induced by intrajugular injection of collagen and epinephrine and caused fatal pulmonary embolism within 5 minutes in

\section{Figure 2}

Loss of Tyro3, AxI, or Mer protects mice against thrombosis. (A) Stasis-induced thrombosis in the inferior vena cava (mean \pm SEM, $n=10)$. ${ }^{*} P<0.005$. (B) Thromboembolism induced by collagen/epinephrine injection in WT $(n=15)$ and in Tyro3 ${ }^{--}(n=15), \mathrm{AxI}^{-1-}(n=10)$, and $\mathrm{Mer}^{-/-}(n=12)$ mice. ${ }^{*} P<0.005$. (C and D) Light microscopy (H\&E staining) of the lungs after collagen/epinephrine injection, revealing extensive platelet thromboemboli (arrows) in WT mice (C) but not in surviving $\mathrm{Axl}^{-1-}$ mice (D) or $\mathrm{TyrO}^{-1-}$ or $\mathrm{Mer}^{-/-}$mice (not shown). Scale bars: $100 \mu \mathrm{m}$.
$80 \%$ of WT mice $(n=15)$. In contrast, fatal pulmonary embolism was observed, after $10-20$ minutes, in only $25 \%$ of Tyro $^{-/-}$mice $(n=15)$, in $10 \%$ of $A x l^{-1-}$ mice $(n=10)$, and in $20 \%$ of $\mathrm{Mer}^{-/-}$mice $\left(n=12, P<0.05\right.$ versus WT for all Gas6- $R^{-1}$ mice; Figure $\left.2 \mathrm{~B}\right)$. Macroscopic and histological analysis revealed extensive pulmonary thromboembolism in WT mice (Figure 2C). In contrast, no signs of pulmonary embolization were detectable in surviving Axl $\mathrm{I}^{-/-}$mice (Figure 2D), or in $\mathrm{Tyro3}^{-/-}$or $\mathrm{Mer}^{-/-}$mice (data not shown). The hemostatic phenotype of Gas6-R-deficient mice was not attributable to genotypic differences in platelet counts, prothrombin and activated partial thromboplastin times, or fibrinogen levels (data not shown).

Although the above model of collagen-induced thromboembolism is recognized to be platelet dependent, we sought to further confirm that the protection against thrombus formation in mice lacking a Gas6-R was predominantly due to altered platelet function. We therefore induced thromboembolism with collagen and epinephrine in $A x^{-/-}$mice after platelet depletion and subsequent reconstitution with either WT or $A x^{l^{-/}}$platelets $(23,24)$. Thrombocytopenia was achieved in $A x l^{-/-}$mice by i.p. injection of $20 \mathrm{mg} / \mathrm{kg}$ busulfan on days 1 and 3 and i.v. injection of anti-platelet $\mathrm{mAb}$ CV-5H7 on day 3 (25). On day 6, platelet counts dropped to less than 10 giga/liter (G/l). Thromboembolism experiments were performed on day 6 after reconstitution of WT or $A x^{l^{-/}}$platelets in $A x l^{-/-}$thrombocytopenic mice (washed platelets from $3 \mathrm{WT}$ or 3

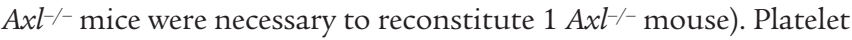
counts in $A x l^{-/-}$mice after reconstitution with WT platelets or $A x^{-/-}$ platelets were $546 \pm 45 \mathrm{G} / \mathrm{l}(n=5)$ and $583 \pm 39 \mathrm{G} / \mathrm{l}(n=5)$, respectively. Fatal pulmonary embolism was observed in 4 of $5 \mathrm{Axl}^{-/-}$ mice reconstituted with WT platelets but, notably, in none of the $A x^{-/-}$mice reconstituted with $A x^{-/-}$platelets. These results confirm that resistance of Gas6-R-deficient mice to thromboembolism may be largely attributed to a platelet-function defect.

Impaired platelet aggregation and clot retraction in $\mathrm{Tyro3}^{-1-}, \mathrm{Axl^{-/ }}$, or $\mathrm{Mer}^{-/-}$mice. Since Gas6 impairs platelet plug formation (7), platelet function of Gas6-R-deficient mice was also studied. Platelets from WT mice dose-dependently aggregated in response to increasing concentrations of ADP, collagen, or the TXA 2 analogue U46619, achieving a maximal effect at concentrations similar to those pre-

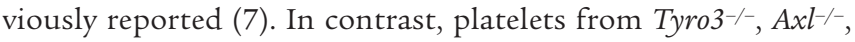
or $\mathrm{Mer}^{-/-}$mice failed to irreversibly aggregate in response to low concentrations of ADP (less than $10 \mu \mathrm{M}$; Figure 3A), collagen
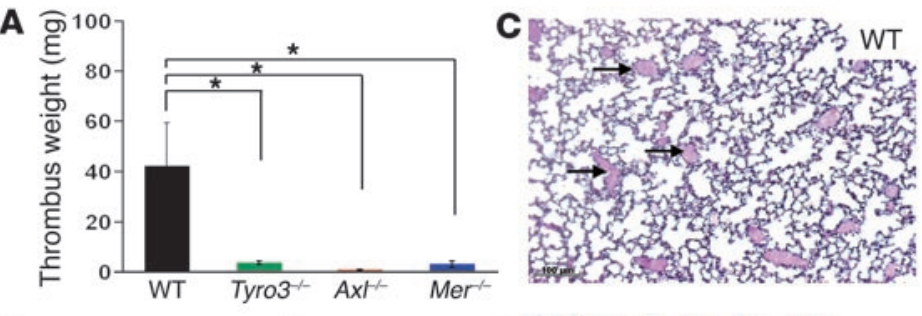

B

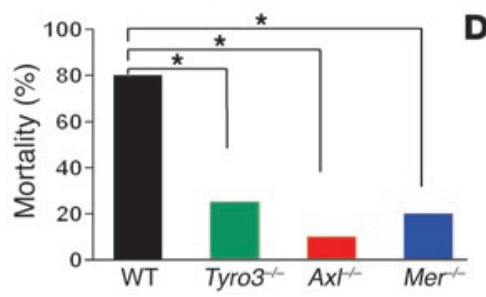

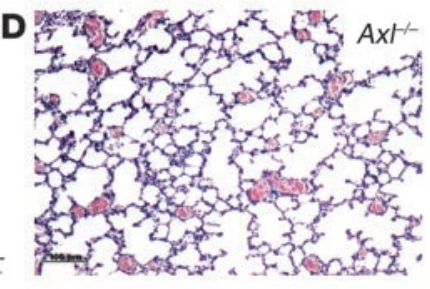




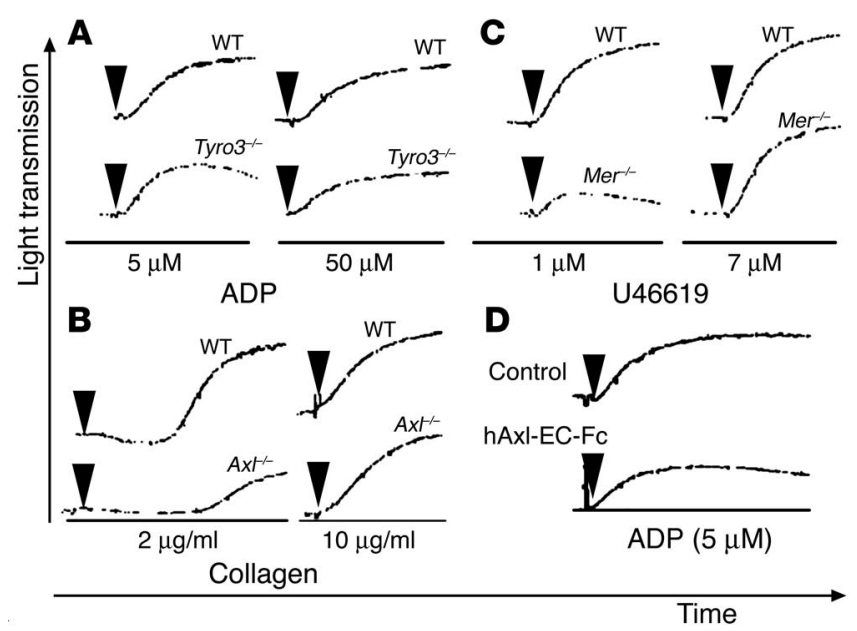

$(2 \mu \mathrm{g} / \mathrm{ml}$; Figure 3B), or U46619 (1 $\mu \mathrm{M}$; Figure 3C), although higher concentrations of these agonists were capable of inducing irreversible aggregation of platelets (Figure 3, A-C). The impaired platelet aggregate formation in Gas6-R-deficient mice resulted from signaling defects most likely upstream of PKC activation or $\mathrm{Ca}^{++}$ mobilization, since WT, Tyro3 ${ }^{--}, \mathrm{Axl}^{-/}$, or $\mathrm{Mer}^{-/-}$platelets aggregated normally in response to PMA or the $\mathrm{Ca}^{++}$ionophore $\mathrm{A} 23187$ (data not shown). Thrombin (0.01-1.0 IU/ml) and the proteaseactivated receptor 4-activating (PAR4-activating) peptide AYPGKF (0.25-1.0 mM) (26) comparably stimulated initial platelet aggregation in all genotypes (data not shown). However, clot retraction upon thrombin treatment was significantly impaired in Tyro3 ${ }^{-/-}$, $\mathrm{Axl}^{-/-}$, or $\mathrm{Mer}^{-/-}$mice (Figure 4). These data establish a key role for the Gas6-Rs in the perpetuation of platelet activation and the stabilization of platelet aggregates.

Normal fibrinogen binding in $\mathrm{Tyro3}^{-/-}, \mathrm{Axl}^{-/}$, or $\mathrm{Mer}^{-/-}$platelets. Since binding of fibrinogen during initial platelet activation - a process that depends on inside-out signaling to $\alpha_{\mathrm{II}} \beta_{3}(27)$ - is critical for platelet aggregation, we examined whether the platelet defect of Gas6-R-deficient mice was attributable to impaired fibrinogen binding. However, fibrinogen binding during initial platelet activation was similar in all genotypes. Indeed, platelets of all genotypes bound comparable amounts of Oregon Green 488-conjugated fibrinogen after stimulation with various concentrations of ADP (1.25-20 $\mu \mathrm{M}$; Figure 5). Thus, loss of a Gas6-R does not seem to affect the initial conversion of $\alpha_{\mathrm{II}} \beta_{3}$ from a low-affinity/lowavidity to a high-affinity/high-avidity receptor upon activation of platelets by various agonists.

Defective outside-in signaling in Tyro3 ${ }^{-/-}, \mathrm{Axl}^{-/-}$, or $\mathrm{Mer}^{-/-}$platelets. To analyze platelet spreading after adhesion to fibrinogen (a process that depends on outside-in signaling via $\alpha_{\mathrm{IIb}} \beta_{3}$ ), unstimulated platelets were incubated on a fibrinogen-coated surface. Notably, fewer platelets from Tyro3 $3^{-/}, \mathrm{Axl}^{\mathrm{l}^{--}}$, or $\mathrm{Mer}^{-/-}$mice adhered to fibrinogen, and these failed to spread out as extensively as WT platelets during the first 15-30 minutes of incubation (Figure 6, A-D). However, after 60 minutes, a comparable number of platelets from WT, Tyro3 ${ }^{-/-}, \mathrm{Axl}^{-/-}$, or $\mathrm{Mer}^{-/-}$mice spread on fibrinogen-coated surface (Figure 6, E and F), indicating that spreading of mutant platelets was impaired but not permanently abrogated. Analysis by video microscopy revealed that $A x^{l^{-/}}$platelets, once they adhered, required longer times to maximally spread than WT platelets $\left(300 \pm 23\right.$ seconds for $A x^{l^{-/}}$platelets versus $160 \pm 11 \mathrm{sec}-$

\section{Figure 3}

Effect of the lack of Tyro3, Axl, or Mer on aggregation of WT, Tyro3 ${ }^{-1}$, $\mathrm{Axl}^{-1-}$, or Mer-l- PRP. (A) Response of WT or Tyro3-1- platelets to $5 \mu \mathrm{M}$ and $50 \mu \mathrm{M}$ ADP. (Similar results were obtained with $\mathrm{Axl}^{-/-}$and $\mathrm{Mer}^{-/-}$ platelets; data not shown.) (B) Response of WT or $\mathrm{Axl}^{-/-}$platelets to $2 \mu \mathrm{g} / \mathrm{ml}$ and $10 \mu \mathrm{g} / \mathrm{ml}$ collagen. (Similar results were obtained with Tyro3 $^{-/-}$and $\mathrm{Mer}^{-/-}$platelets; data not shown.) (C) Response of WT or $\mathrm{Mer}^{--}$platelets to $1 \mu \mathrm{M}$ and $7 \mu \mathrm{M} \mathrm{TXA}$ analogue U46619. (Similar results were obtained with $\mathrm{TyrO}^{-/-}$and $\mathrm{Ax}^{H^{--}}$platelets; data not shown.) (D) Aggregation response to ADP $(5 \mu \mathrm{M})$ of washed human platelets after preincubation with human Axl extracellular domain (hAxl-EC-Fc) or control IgG, revealing that $\mathrm{hAxl}-\mathrm{EC}-\mathrm{Fc}$ reduces platelet aggregation. A representative example of 3 independent experiments is shown. Arrows in $\mathbf{A}-\mathbf{D}$ indicate addition of the platelet agonists.

onds for WT platelets; $n=50, P<0.05$; Figure 7A). Moreover, when the cellular area of the platelets was measured at various times after spreading, $A \times l^{-/-}$platelets were smaller than WT platelets at any time point, which again indicated that platelet spreading was impaired in the absence of Axl (Figure 7B). These findings are in agreement with the impaired clot retraction observed with Tyro3 ${ }^{-1}$, $A x l^{-/}$, and $\mathrm{Mer}^{-/-}$platelet-rich plasma (PRP) clots (Figure 4).

Defective platelet secretion in Tyro3 ${ }^{-1-}, \mathrm{Axl}^{-/}$, or $\mathrm{Mer}^{-/-}$platelets. We previously documented a close correlation between the impaired aggregation and the secretion response of $\mathrm{Gas}^{-/-}$platelets to various agonists and therefore measured the secretion response of $\mathrm{Tyro3}^{-/-}, \mathrm{Axl}^{-/-}$, or $\mathrm{Mer}^{-/-}$platelets (7). Secretion of ADP from dense granules is essential for the formation of stable macroaggregates after initial formation of small, unstable platelet aggregates. This is accompanied by secretion of adhesion proteins such as fibrinogen, vWFa, and P-selectin from $\alpha$ granules, which further contributes to stable platelet plug formation. Secretion of dense-granule stores (evaluated by measurement of the amount of released

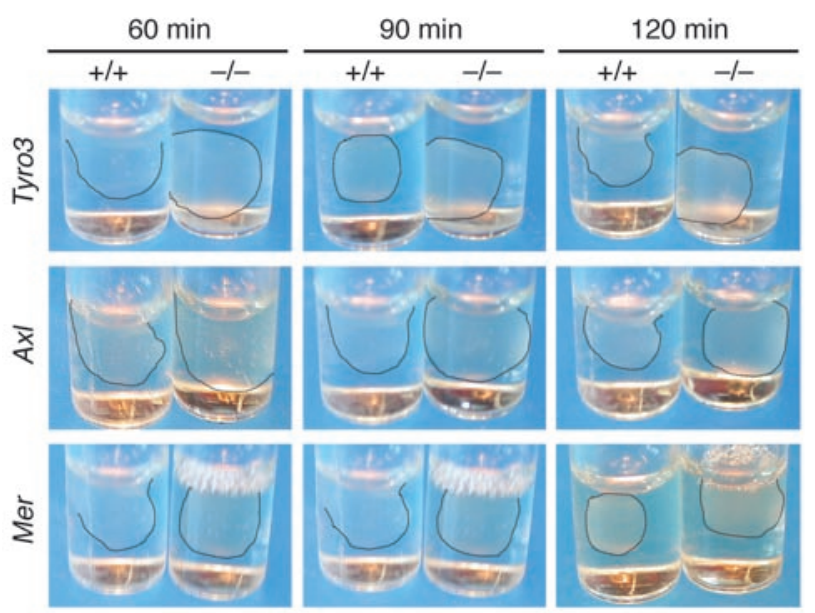

Figure 4

Effect of the lack of Tyro3, Axl, or Mer on clot retraction. Photographs show the degree of clot retraction after 60,90, and 120 minutes in WT, Tyro3 ${ }^{---}, \mathrm{AxI}^{-/-}$, and $\mathrm{Mer}^{-/-}$PRP samples treated with $10 \mathrm{IU} / \mathrm{ml}$ thrombin. Tyro3 ${ }^{-/}, \mathrm{Axl}^{-/-}$, and $\mathrm{Mer}^{-/-}$PRP was slower than WT PRP in retracting clots $(n=3)$. Clots are surrounded by dotted lines. 

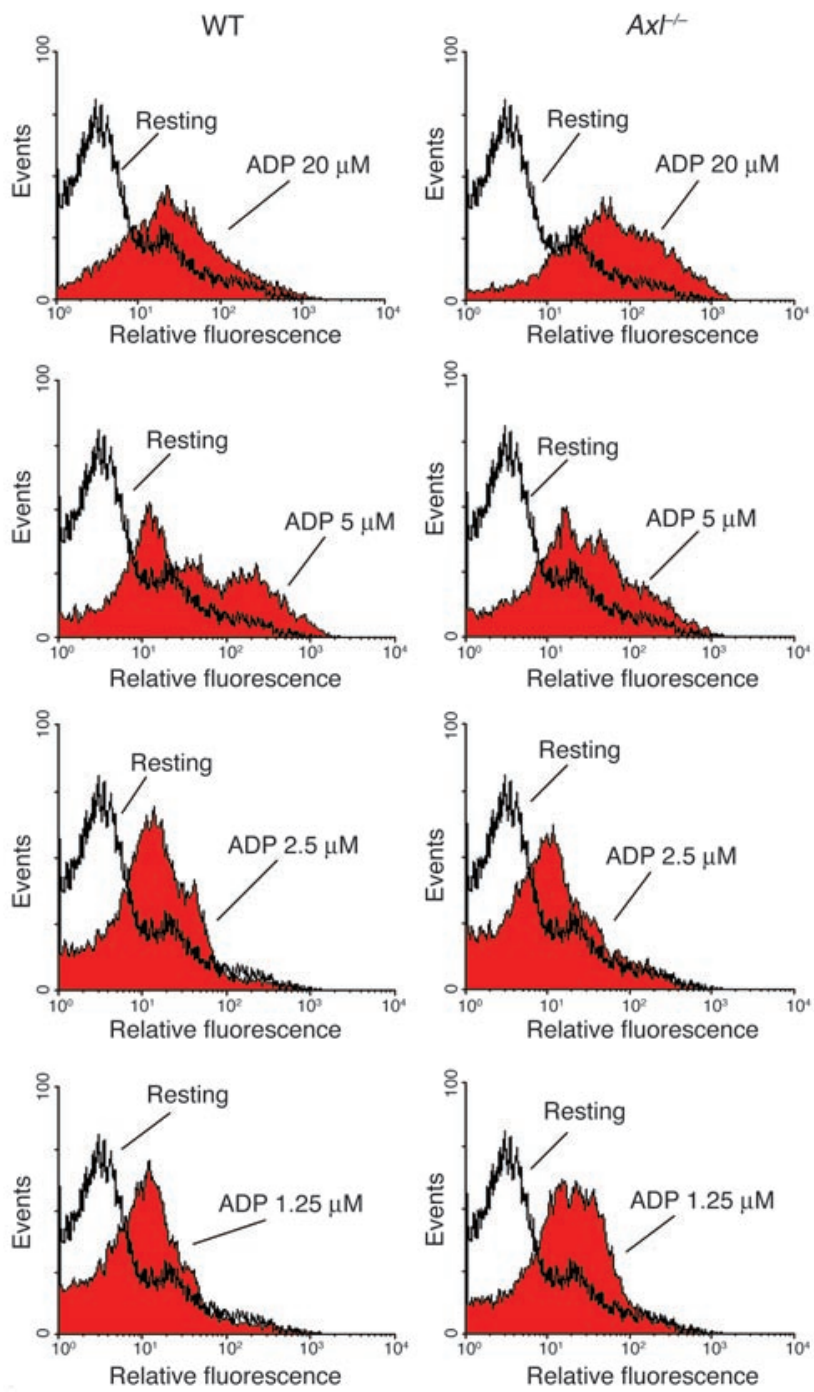

Figure 5

Effect of the lack of Tyro3, Axl, or Mer on fibrinogen binding. Loss of 1 Gas6-R (results shown for $A x^{-1-}$ mice) does not inhibit fibrinogen binding to $\alpha_{\| 1 b} \beta_{3}$ integrin. The binding of labeled fibrinogen to platelets activated with ADP $(1.25-20 \mu \mathrm{M})$ was measured by flow cytometry. Black lines denote resting platelets; red shading denotes ADP-stimulated platelets. A representative example of 4 independent experiments is shown.

ATP) in response to $2 \mu \mathrm{g} / \mathrm{ml}$ collagen was significantly impaired in Tyro $3^{-1-}$ platelets $(9.9 \pm 0.7 \mu \mathrm{M}$ ATP from WT platelets versus $5.3 \pm 0.2 \mu \mathrm{M}$ ATP from Tyro3 ${ }^{-/-}$platelets; $\left.n=3, P<0.05\right)$. Secretion of $\alpha$ granules, assessed by measurement of the surface levels of P-selectin during platelet activation, was also impaired in Tyro $3^{-/-}$, $\mathrm{Axl}^{-/-}$, or $\mathrm{Mer}^{-/-}$platelets in response to low concentrations of ADP (Figure 8). Thus, defects in granule secretion may also contribute to the phenotypes of Gas6-R deficiency.

Gas6 stimulates tyrosine phosphorylation of the $\beta_{3}$ integrin. The above findings that Gas6-Rs regulate spreading of platelets on fibrinogen and stabilization of the platelet plug suggested that Gas6-R signaling influenced outside-in signaling by the $\alpha_{\mathrm{II}} \beta_{3}$ integrin. Upon ligand binding, critical tyrosine residues in the cytoplasmic tail of the $\beta_{3}$ integrin become phosphorylated, which then serve as docking sites for downstream signaling molecules. We therefore inves- tigated the effect of Gas 6 on $\beta_{3}$ integrin tyrosine phosphorylation by immunoblotting using anti- $\beta_{3}\left[\mathrm{pY}^{773}\right]$ phosphospecific antibodies. Since Gas6, by itself, is unable to promote platelet aggregation (7), treatment of platelets with Gas6 permitted us to study $\alpha_{\mathrm{II}} \beta_{3}$ tyrosine phosphorylation independently of platelet aggregation. As shown in Figure 9A, treatment of resting platelets with Gas 6 stimulated $\beta_{3}$ integrin tyrosine phosphorylation in WT platelets. In contrast, such $\beta_{3}$ tyrosine phosphorylation did not occur when $\mathrm{Tyro3}^{-/_{-}}$(Figure 9A), or $\mathrm{Axl}^{\mathrm{l}^{--}}$or $\mathrm{Mer}^{-/-}$(data not shown), platelets were treated with Gas6. The reduced $\beta_{3}$ tyrosine phosphorylation in Gas6-R-deficient platelets was not attributable to a decrease in total $\beta_{3}$ integrin expression, as shown by flow cytometry (Figure 9B). Gas6-R signaling determined the degree of $\beta_{3}$ phosphorylation not only in resting platelets, but also in activated platelets after stimulation with thrombin. Indeed, when WT platelets were stimulated with thrombin (which is known to enhance release of Gas6 from the endogenous platelet stores; see ref. 7 ), the $\beta_{3}$ integrin became tyrosine-phosphorylated (Figure 9C). Quantification by densitometry revealed that a lower percentage of the total amount of $\beta_{3}$ was tyrosine-phosphorylated $(30 \% \pm 4 \%$ and $30 \% \pm 4 \%$ in WT platelets versus $8 \% \pm 2 \%$ and $20 \% \pm 2 \%$ in Tyro $^{-/-}$platelets after 0.05 and 0.10 IU thrombin/ $\mathrm{ml}$, respectively; $n=3, P<0.05$ ). Absence of Gas6-R significantly reduced but did not, however, abolish tyrosine phosphorylation of the $\beta_{3}$ integrin, as higher concentrations and longer times of application of thrombin did stimulate phosphorylation of the $\beta_{3}$ integrin (Tyro3 ${ }^{-/-}$, Figure 9C; $\mathrm{Axl}^{\mathrm{l}^{--}}$and $\mathrm{Mer}^{-/-}$, data not shown). Thus, Gas6-R signaling determines $\beta_{3}$ tyrosine phosphorylation and, thereby, also outside-in signaling of $\alpha_{\mathrm{IIb}} \beta_{3}$, defects of which result in retarded platelet spreading on fibrinogen.

Gas6 stimulates phosphorylation of its receptors. Since some of the effects of the Gas6-Rs have been proposed to be ligand-independent and to not require tyrosine phosphorylation of the receptors (28), we analyzed whether Gas6 enhanced the kinase activity of Tyro3, Axl, and Mer. Immunoprecipitation using phosphotyrosine antibodies and subsequent immunoblotting using Gas6-R-specific antibodies revealed that Gas6 induced tyrosine phosphorylation of Tyro3 (data not shown), Axl (Figure 9A), and Mer (data not shown) in WT platelets. As expected, when a particular Gas6-R (for instance Axl) was absent, it could not be immunoprecipitated. Remarkably, however, absence of Tyro3 prevented ligand-induced tyrosine phosphorylation of the 2 other Gas6-Rs (Axl, Figure 9A; and Mer, data not shown). Similarly, when Axl or Mer was absent, Gas6-induced tyrosine phosphorylation of the residual Gas6-R failed to occur, suggesting that the Gas6-Rs cooperate in their activation response (see below).

As this might be due to interdependent expression patterns of each of the Gas6-Rs, we analyzed by flow cytometry the expression level of Gas6-Rs that are capable of binding Gas6, on the surface of resting platelets from WT mice or mice lacking any 1 of the Gas6-Rs. Platelets were incubated with recombinant myc-tagged Gas6 (Gas6-myc), and binding of Gas6-myc was measured by flow cytometry using an anti-myc antibody. As shown in Figure 10, Gas6-myc was found to bind to WT platelets, while only negligible amounts of Gas6-myc bound to Tyro3 ${ }^{--}, \mathrm{Axl}^{---}$, or $\mathrm{Mer}^{-/-}$platelets. These findings thus reveal that, in the absence of 1 Gas6-R subtype, the expression of the other Gas6-Rs is also minimal. To confirm that the expression of the Gas6-Rs was indeed regulated in an interdependent manner, we measured by flow cytometry, using an anti-Axl antibody, the expression level of $\mathrm{Axl}$ (as a prototype of the Gas6-Rs) on platelets. 

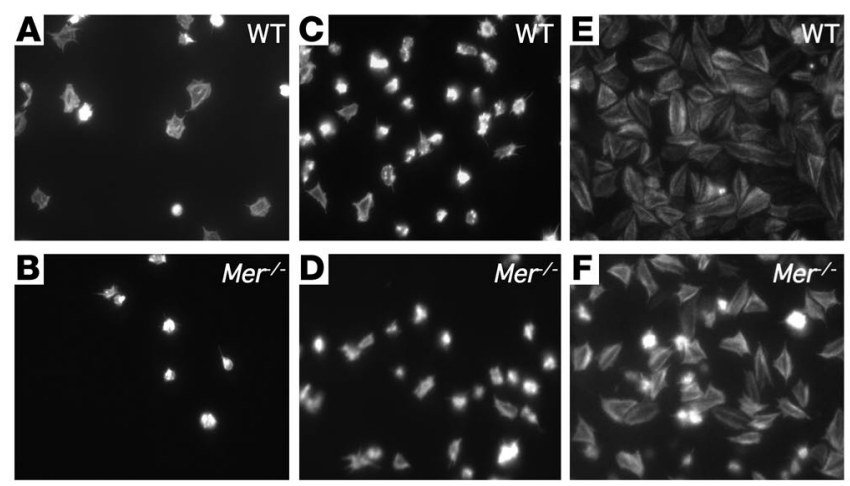

Figure 6

Delayed Tyro3---, $\mathrm{Axl}^{-1-}$, or $\mathrm{Mer}^{-/-}$platelet spreading on immobilized fibrinogen. WT or $\mathrm{Mer}^{-1-}$ platelets (similar results were obtained with Tyro3 ${ }^{--}$and $\mathrm{Axl}^{---}$platelets) were incubated on a fibrinogen-coated surface for 15 minutes (A and $\mathbf{B}$ ), 30 minutes (C and $\mathbf{D})$, and 60 minutes ( $\mathbf{E}$ and $\mathbf{F})$ without agonist and stained with rhodamine-phalloidin to visualize actin. A representative example of 3 independent experiments is shown. Field width: $50 \mu \mathrm{m}$.

As expression of Axl on the surface of resting platelets was below the detection limit of this assay (data not shown), we stimulated platelets with the PAR4-activating peptide $(0.25 \mathrm{mM})$. Activated WT platelets expressed detectable levels of Axl on their surface, while, as expected, Axl was absent from activated $A x l^{-/-}$platelets (Figure 11). Notably, however, activated $\mathrm{Tyro3}^{-/-}$platelets and $\mathrm{Mer}^{-/-}$platelets expressed only minimal amounts of Axl on their surface (Figure 11). Similar results were obtained from analysis of the expression of Tyro3 (platelets expressing Tyro3 in WT mice, $77 \% \pm 4 \%$; in Tyro3 ${ }^{-1-}$ mice, $6 \% \pm 0.5 \%$; in $A x^{-/-}$mice, $38 \% \pm 6 \%$; and in $\mathrm{Mer}^{-/-}$mice, $34 \% \pm 4 \%$; mean \pm SEM, $n=3, P<0.05$ ) or Mer (platelets expressing Mer in WT mice, $70 \% \pm 3 \%$; in Tyro3 ${ }^{-/-}$mice, $39 \% \pm 2 \%$; in $A x l^{-/-}$mice, $35 \% \pm 3 \%$; and in $\mathrm{Mer}^{-/-}$mice, $9 \% \pm 0.6 \%$; mean \pm SEM, $\left.n=4, P<0.05\right)$. Thus, lack of any 1 of the Gas6-Rs significantly reduced the expression of the other Gas6-Rs on the surface of platelets and, thus, the capacity to bind and respond to activation by Gas6.

Gas6 signaling activates PI3K and Akt. The signaling pathway, downstream of Gas6-R activation, was further investigated. The Gas6 pathway does not seem to influence the eicosanoid synthesis pathway, as $\mathrm{Gas}^{-/-}$platelets produce normal amounts of $\mathrm{TXA}_{2}$ (7) and Gas6-R signaling in other cell types requires PI3K and Akt (18-20). We therefore analyzed whether Gas6-R signaling might activate PI3K and Akt, as the PI3K pathway is involved in $\alpha_{\mathrm{IIb}} \beta_{3}$ activity regulation in platelets (4, 29). Indeed, Gas6 was found to enhance phosphorylation of PI3K and Akt in resting WT platelets, but not in $\mathrm{Tyro3}^{--}$(Figure 9A),
A
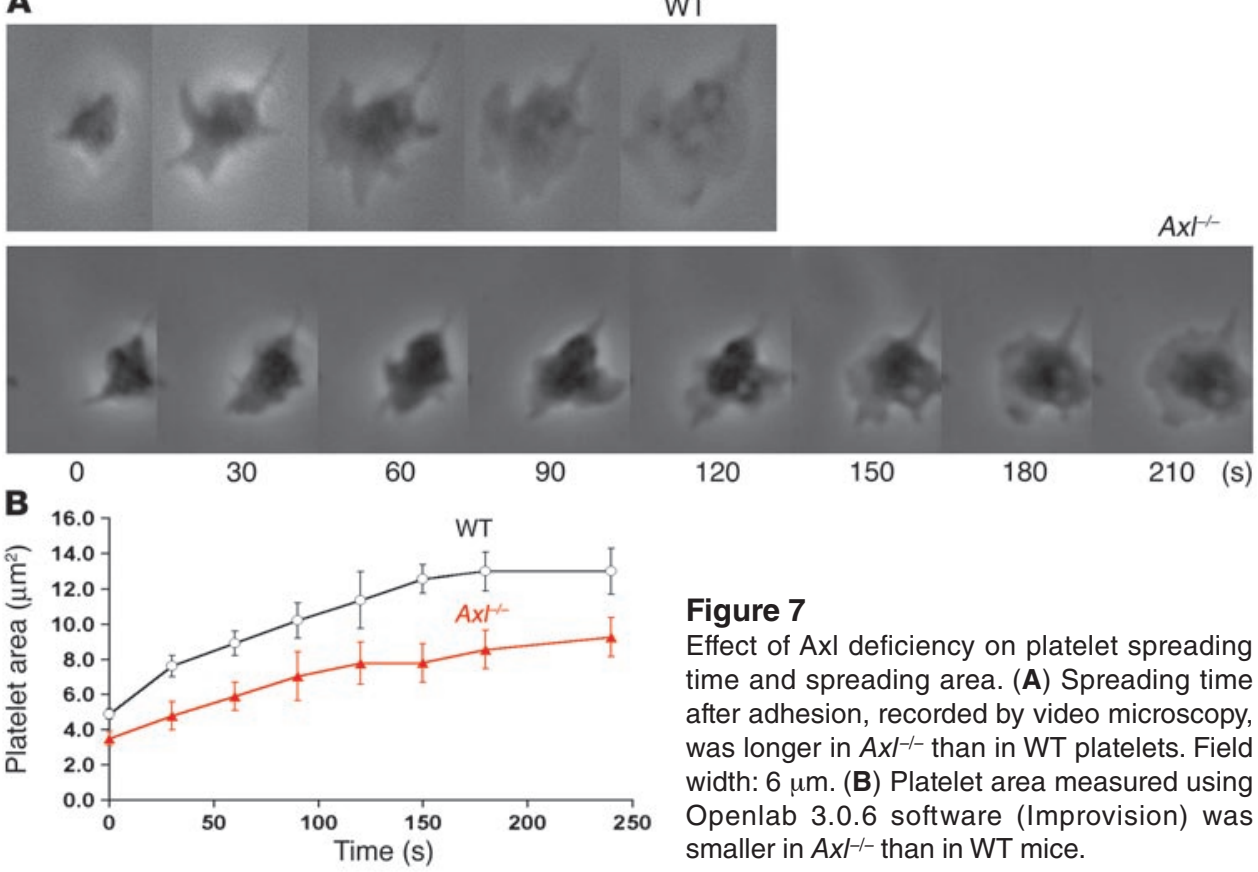

$A x l^{-/-}$, or $\mathrm{Mer}^{-/-}$(data not shown) platelets, indicating that each Gas6-R is critical for signal transduction of Gas6. The Akt pathway is also well known to play a key role in response to thrombin. In WT platelets, Akt phosphorylation was already increased within 30 seconds after activation with $0.05 \mathrm{IU} / \mathrm{ml}$ thrombin (Figure 12). In contrast, Akt phosphorylation in Tyro $^{3^{--}}, A x^{l^{--}}$, (data not shown), and $\mathrm{Mer}^{-/-}$(Figure 12, A and B) platelets occurred only after 3 minutes, and only when the platelets were stimulated with a 10 -fold higher concentration of thrombin $(0.5 \mathrm{IU} / \mathrm{ml}$; Figure 12, A and B). Thus, phosphorylation of Akt was impaired in platelets lacking any 1 of the Gas6-Rs.

The soluble Axl extracellular domain inhibits platelet function. We next assessed the therapeutic potential of blocking the Gas6-R-dependent amplification of outside-in signaling via $\alpha_{\mathrm{IIb}} \beta_{3}$ by using the soluble Axl extracellular domain (hAxl-EC-Fc), which traps Gas6. The aggregation of WT platelets in response to $\mathrm{ADP}(5 \mu \mathrm{M})$ was dose-dependently blocked by hAxl-EC-Fc. In contrast, hAxl-EC-FC had no effect on WT platelets in the absence of ADP (Figure 3D). Administration of $0.75 \mathrm{mg} / \mathrm{kg}$ hAxl-EC-Fc significantly protected WT mice against fatal collagen/epinephrine-induced pulmonary thromboembolism. Indeed, $60 \%$ of the mice receiving hAxl-EC-Fc survived, whereas none of the mice receiving control vehicle survived $(n=7, P<0.05)$. Mice treated with hAxl-EC-Fc did not spontaneously bleed, nor were their bleeding times prolonged (data not shown). These results indicate that inhibition of Gas6-R signaling by trapping of its ligand effectively prevents thrombosis.

\section{Discussion}

We recently reported that loss of Gas6 protected mice against pathological thrombosis by preventing the formation of stable platelet plugs during the perpetuation phase of platelet activation (7). The findings of the present study that we believe to be novel are: (a) each of the Gas6-Rs (Tyro3, Axl, and Mer) is necessary to transmit the platelet-stabilization effect of Gas 6 in vitro, whereas absence of any of these Gas6-Rs protects mice against pathologi- 

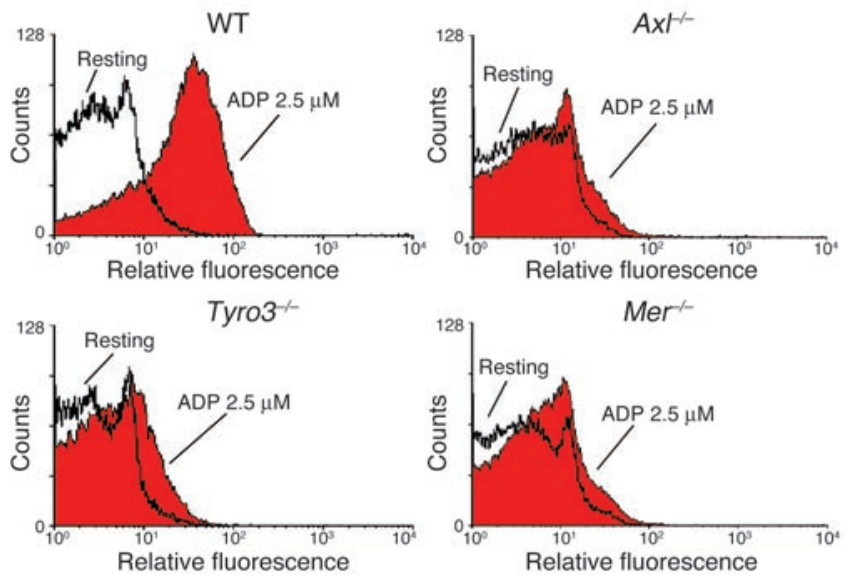

cal thrombosis in vivo; (b) Gas6-R signaling appears to affect outside-in signaling via the $\alpha_{\mathrm{II}} \beta_{3}$ integrin and to regulate granule secretion; and (c) activation of Gas6-R by Gas6 activates PI3K and stimulates tyrosine phosphorylation of $\beta_{3}$ integrin. These genetic studies provide novel insight into the poorly understood physiological importance of outside-in signaling, which is critical for the formation of stable platelet plugs and clot retraction.

Gas6- $R^{-/-}$mice are phenocopies of Gas $6^{-/-}$mice. Mice lacking any 1 of the 3 Gas6-Rs (Tyro3, Axl, or Mer) have normal initial bleeding times and are resistant to thrombosis, but they do not suffer spontaneous bleeding. Their resistance to thrombosis was not due to impaired megakaryocytopoiesis or defects in the coagulation cascade but was due, at least in part, to platelet dysfunction. As Gas6 seems to regulate also the expression of tissue factor on activated endothelial cells (E.M. Conway and P. Carmeliet, unpublished observations), we cannot exclude the possibility that Gas6-Rs also contribute to thrombus formation via such a mechanism. However, the platelet transfusion experiments clearly indicate that the antithrombotic phenotype in Gas6-R-deficient mice is, at least in part, attributable to a platelet defect. In the absence of a Gas6-R, low concentrations of ADP, collagen, or $\mathrm{TXA}_{2}$ induced reversible platelet aggregation, while high concentrations of these platelet agonists caused irreversible platelet aggregation. In addition, low concentrations of thrombin or the PAR4-activating peptide stimulated platelet aggregation. Thus, aggregation of platelets could occur but was less efficient in platelets lacking any 1 of the Gas6-Rs. Irreversible aggregation of Gas6-R-deficient platelets required higher concentrations of platelet agonists or a potent agonist such as thrombin. Thus, Gas6-R $R^{-/-}$mice are phenocopies of Gas $6^{-/-}$mice (7). Overall, the antithrombotic effect of the lack of Gas6 or a Gas6-R is comparable to that of aspirin, when assayed in the same thromboembolism model (30).

\section{Figure 8}

Effect of the absence of Tyro3, Axl, or Mer on P-selectin expression, a marker of $\alpha$ granule secretion. Analysis by flow cytometry revealed that $\mathrm{P}$-selectin levels on the platelet surface were significantly reduced in Tyro3 $^{-/}, \mathrm{Axl}^{-/-}$, or $\mathrm{Mer}^{-/-}$platelets, after activation with ADP. Black lines denote resting platelets; red shading denotes ADP-stimulated platelets. A representative example of 3 independent experiments is shown.

A remarkable finding was, however, that deficiency of any of the Gas6-Rs protected mice against thrombosis to the same significant extent, which suggests that each of these receptors has a comparably important role in platelet aggregation. Even more, Gas6 was capable of inducing tyrosine phosphorylation of each Gas6-R, but absence of 1 Gas6-R prevented tyrosine phosphorylation of the 2 other Gas6-Rs. An explanation for the latter phenomenon is provided by the observation that substantial amounts of Gas6-R reached the platelet surface only during platelet activation and that the lack of any 1 of the Gas6-Rs dramatically reduced the surface expression of the other receptors. As a result, the binding of Gas6 to Gas6-Rs on the platelet surface was significantly reduced to negligible residual levels when 1 of these Gas6-Rs was absent. These findings suggest that Gas6-Rs somehow cross-talk to each other to codetermine their surface exposure and responsiveness to Gas 6 (i.e., binding of ligand, stimulation of receptor tyrosine kinase activity). Thus, the exposure of any 1 of the Gas6-Rs appears to
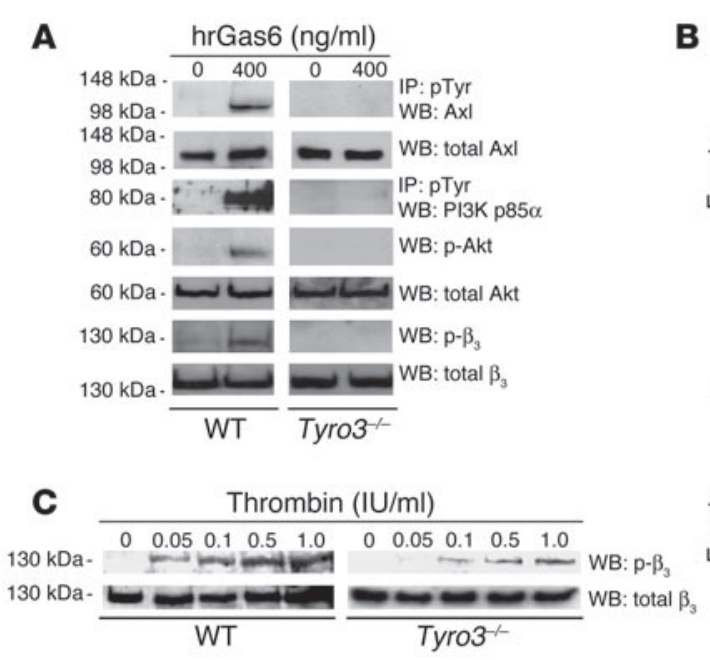

\section{Figure 9}

Gas6 signaling through its receptors Tyro3, Axl, and Mer. (A) Gas6 promotes phosphorylation of its receptors (shown for AxI), PI3K, Akt, and $\beta_{3}$ integrin in WT but not in Tyro3-/, $A x l^{-/-}$(not shown), or $\mathrm{Mer}^{-1-}$ (not shown) platelets. Platelets were incubated with $400 \mathrm{ng} / \mathrm{ml}$ human recombinant Gas6 (hrGas6) for 3 minutes. For detection of AxI or PI3K phosphorylation, platelets were lysed and phosphotyrosine-containing proteins were immunoprecipitated. The precipitates were then separated by SDS-PAGE and Western-blotted (WB) with anti-AxI or anti-PI3K antibodies. For Akt and $\beta_{3}$ integrin phosphorylation studies, lysed platelets in sample buffer were subjected to SDS-PAGE and Western-blotted with anti-phospho-Akt antibody, anti-total Akt antibody, anti- $\beta_{3}$ integrin [pY773] phosphospecific antibody, or anti- $\beta_{3}$ integrin antibody. (B) $\beta_{3}$ Integrin levels measured by flow cytometry were comparable on the surface of WT and Tyro3 $3^{-1}, \mathrm{Axl}^{-/-}$, or $\mathrm{Mer}^{-1-}$ platelets (only Tyro3-1- data are shown). Black lines denote controls; red shading denotes platelets stained with PE-conjugated anti- $\beta_{3}$ integrin antibody. A representative example of 3 independent experiments is shown. (C) $\beta_{3}$ Integrin tyrosine phosphorylation in response to thrombin in WT and Tyro3 ${ }^{-/}$platelets. Platelets were stimulated with increasing concentrations of thrombin for 3 minutes. A representative example of 3 independent experiments is shown. 

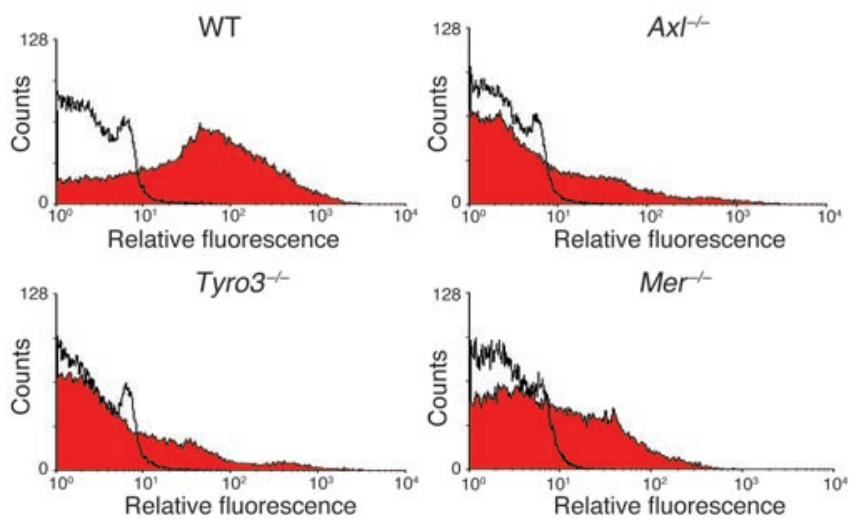

Figure 10

Effect of the absence of Tyro3, Axl, or Mer on Gas6 binding. Analysis by flow cytometry revealed that binding of myc-tagged recombinant Gas6 to resting platelets was significantly lower in Tyro3-1-, $\mathrm{Axl}^{-/-}$, or $\mathrm{Mer}^{-1}$ than in WT platelets. Black lines denote negative control (PBS); red shading denotes binding of myc-tagged Gas6, detected by FITCconjugated anti-myc-tag antibody. A representative example of 3 independent experiments is shown.

be regulated by each of the others. While the present data indicate that each Gas6-R has a significant role in hemostasis on its own (other gene-inactivation studies also indicated that loss of a single Gas6-R can lead to a significant phenotype; see refs. 31, 32), our data obviously do not exclude the possibility that these Gas6-Rs might cooperate in an additive manner, as they do in the regulation of spermatogenesis and innate immunity $(21,33)$. In fact, the experimental conditions used here were not set up to unveil an additive or synergistic interaction. Genetic intercrosses among the Gas6-R-deficient mice, in combination with more severe thrombotic models, might allow us to address these outstanding questions in the future.

Absence of a Gas6-R impairs outside-in signaling. Platelets lacking Tyro3, Axl, or Mer bound normal amounts of fibrinogen in response to ADP. While these findings are consistent with a model whereby Gas6-R signaling would not be necessary for initial activation of $\alpha_{\mathrm{IIb}} \beta_{3}$ by inside-out signaling, the present data do not exclude the possibility that Gas6-R signaling might modulate this process at a later stage. In fact, our data indicate that the Gas6-R signaling was required for tyrosine phosphorylation of the $\beta_{3}$ integrin and thus for outside-in $\alpha_{\mathrm{II}} \beta_{3}$ signaling. Such a model also explains why mice lacking any 1 of the Gas6-Rs had a tendency to rebleed after transient hemostasis and had delayed platelet spreading and clot retraction, processes consistent with a defect in regulation of outside-in $\alpha_{\mathrm{IIb}} \beta_{3}$ signaling (1). The platelet dysfunction caused by absence of a Gas6-R resembles that of mice in which the cytoplasmic tyrosine residues of the $\beta_{3}$ integrin subunit were mutated to phenylalanine (DiYF mice) (2). Both DiYF mice and Gas6-R-deficient mice exhibit normal fibrinogen binding and a normal first wave of ADP-induced platelet aggregation. In contrast, outside-in signaling in DiYF and Gas6-R-deficient platelets was impaired, as they spontaneously disaggregated following initial aggregation in response to ADP. Both strains also had defective clot retraction upon thrombin treatment and showed a tendency to rebleed after initial cessation of bleeding. A difference between the DiYF and the Gas6-R-deficient phenotypes is that Gas6-Rdeficient platelets were able to overcome their defect when stimu- lated by a high dose of platelet agonists for a long duration; this indicates that the absence of a Gas6-R caused a milder outside-in signaling defect than the DiYF mutation did. Our findings obviously do not exclude the possibility that Gas6-R signaling might be involved in additional mechanisms, regulating platelet plug stability and clot retraction. In fact, our data that Gas6-Rs also regulate the process of secretion from dense and $\alpha$ platelet granules and activate PI3K and Akt could imply that perpetuation of the platelet plug might be amplified by upregulation of $\beta_{3}$ integrin activity, leading to enhanced platelet aggregate stability.

Gas6- $R$ signaling. Activation of the Gas6-Rs stimulated phosphorylation of PI3K and Akt (34). PI3K plays an important role in strengthening platelet aggregation during the irreversible phase of aggregation $(35,36)$. Taken together, our data are consistent with a model whereby Gas6, secreted by activated platelets, amplifies fibrinogen-induced platelet spreading, irreversible platelet aggregation, and clot retraction by inducing signals that lead to phosphorylation of Gas6-Rs, which in turn activate PI3K and Akt. How serine and threonine phosphorylation, and subsequently tyrosine phosphorylation of the cytoplasmic tail of $\beta_{3}$ integrin, are precisely modulated via Gas6-R activation remains to be further investigated but might involve intermediate activation of PI3K and Akt in association with integrin-linked kinase displacement toward $\alpha_{\mathrm{IIb}} \beta_{3}$ (4).

Gas6/Gas6-R signaling: a novel class of platelet modifiers. Deficiency of the $\beta_{3}$ integrin $(37,38)$, of either of the purinergic receptors P2Y1 $(39,40)$ and P2Y12 (41), of the GTP-binding Gaq (42), or of protease-activated receptor 3 (PAR3) or PAR4 $(26,43)$ protects mice against thrombosis but also causes bleeding. Deficiency of Gas 6 or any of its receptors also protected mice against thrombosis but did not prolong the bleeding time after tail clipping. In this respect, the effect of Gas6-R signaling resembles that of Eph kinases and ephrins (5) and CD40 ligand (44). Whereas Gas6 by itself is not able to promote platelet aggregation (7), Gas6 signal-
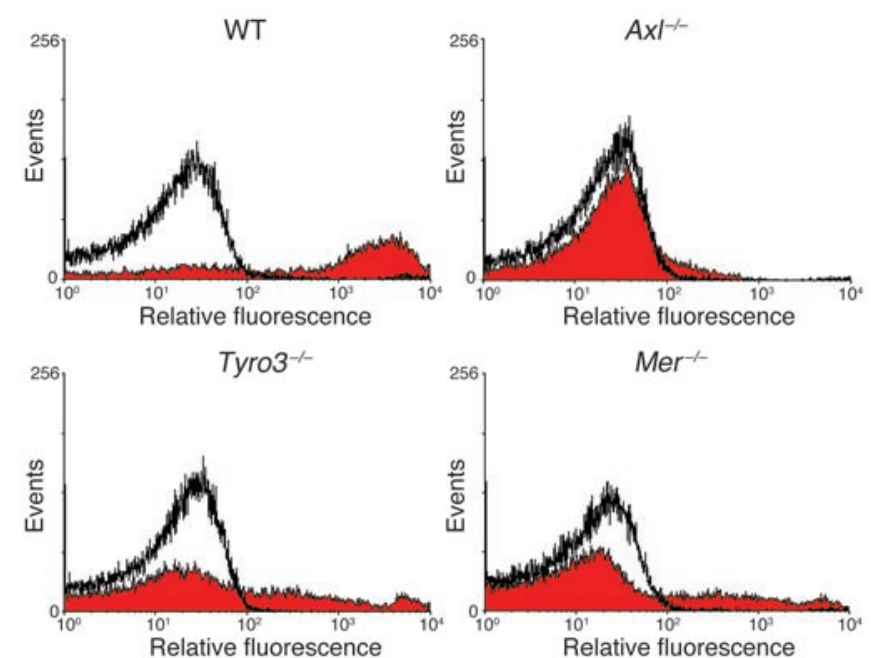

\section{Figure 11}

Axl expression on the surface of WT, Tyro3-1-, Axl-/-, or $\mathrm{Mer}^{-/-}$platelets, activated by the PAR4-activating peptide AYPGKF $(0.25 \mathrm{mM})$. Flow cytometry revealed that surface expression of AxI was dramatically reduced in platelets lacking any 1 of the Gas6-Rs as compared with WT platelets. Axl expression was not detected on the surface of activated $\mathrm{AxI}^{--/}$platelets. Black lines denote isotype-matched control; red shading denotes Axl. A representative example of 3 independent experiments is shown. 
A

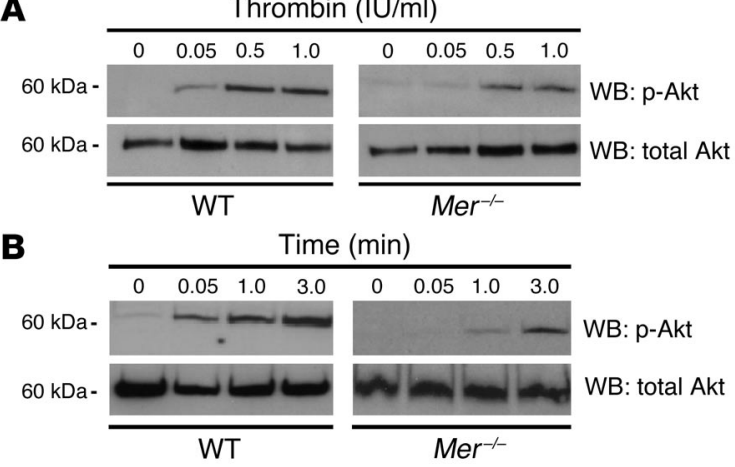

Figure 12

Akt phosphorylation in response to thrombin in WT and $\mathrm{Mer}^{-1-}$ platelets. (Similar results were obtained with $\mathrm{Tyro3}^{-/-}$and $\mathrm{Ax} \mathrm{I}^{-/-}$platelets; data not shown.) (A) Platelets were stimulated with increasing concentrations of thrombin for 3 minutes. (B) Time course of $1 \mathrm{lU} / \mathrm{ml}$ thrombin. A representative example of 3 independent experiments is shown.

ing is critical for platelet function during the late phase of platelet activation, when platelets come into close contact with each other. Gas6 perpetuates platelet activation by enhancing PI3K, Akt, granule secretion, and $\beta_{3}$ integrin signaling. Gas 6 thus belongs to a class of molecules that are redundant for base-line hemostasis but that constitute an important "amplification" system in pathological conditions. Abnormal Gas 6 signaling through 1 or several of its receptors might contribute to bleeding disorders due to a platelet dysfunction. Conversely, abnormal activation of the Gas6 pathway might also contribute to disease phenotypes due to platelet activation (e.g., heparin-induced thrombocytopenia, anti-phospholipid antibody syndrome) that are characterized by thrombosis. A very recent study indicates a significant association between a Gas6 polymorphism and ischemic stroke, placing Gas 6 as a promising candidate for a susceptibility gene for this disease (45).

Medical implications. Based on the critical role of $\alpha_{\mathrm{IIb}} \beta_{3}$ in platelet function, pharmacological inhibitors of ligand binding to $\alpha_{\mathrm{IIb}} \beta_{3}$ have been developed to prevent thrombosis. With the exception of recombinant antibodies that block fibrinogen binding to $\alpha_{\mathrm{II}} \beta_{3}$ and therefore aggregation as well as outside-in signaling, all currently available antiplatelet drugs are specific inhibitors of inside-out signaling. For example, aspirin inhibits COX-1 and, consequently, the production of TXA 2 , while clopidogrel antagonizes signaling through the P2Y12 receptor (46). Drugs designed to prevent irreversible platelet aggregation rather than inhibition of formation of platelet aggregates are currently not available. Our findings indicate that inhibition of Gas6, involved in the signaling pathways controlling irreversible aggregation, could be a novel treatment paradigm. Indeed, a soluble Axl extracellular domain protected mice against fatal thromboembolism without bleeding side effects. Axl extracellular domain therefore provides a novel and relatively safe means to prevent thrombosis.

\section{Methods}

Materials. Busulfan, ADP, U46619, and A23187 were from Sigma-Aldrich. Collagen was from Hormon Chemie. The PAR4 agonist peptide AYPGKF was synthesized by Bachem AG.

Mice. Tyro3 ${ }^{-/-}, \mathrm{Axl}^{-/}$, and $\mathrm{Mer}^{-/}$mice were progeny of the original colony of 50\% $129 / 50 \%$ C57BL/ 6 mice (21). WT mice used as controls had the same genetic background. Ethical approval for the animal experiments detailed in this article was received from the Institutional Animal Care and Research
Advisory Committee of the University of Leuven and the Ethical Committee for Animal Experiments of the Medical Faculty of the University of Geneva.

Hemostasis. We measured bleeding by $2-\mathrm{mm}$ tail-tip transection in mice anesthetized by i.p. injection of a mixture of ketamine $(80 \mathrm{mg} / \mathrm{kg})$ and xylazine $(16 \mathrm{mg} / \mathrm{kg})$. We used 2 models of bleeding time. For the first model, a stopwatch was started immediately upon transection to determine time to cessation of bleeding. Blood drops were removed every 30 seconds using a filter paper. If bleeding did not recur within 60 seconds of cessation, bleeding was considered stopped. The second model was used to detect rebleeding after initial hemostasis. For quantitative estimation of the amount of blood loss per time unit after tail transection, the cut end of the tail was immediately immersed in $20 \mathrm{ml}$ normal saline at $37^{\circ} \mathrm{C}$. Aliquots of saline solution containing blood were sampled every minute for 10 minutes and then every 5 minutes until 30 minutes. Red blood cells were lysed using Zap-Oglobin II lytic reagent (Beckman Coulter Inc.), and samples were read at $405 \mathrm{~nm}$ (to measure the hemoglobin content). A quantitative estimation of the amount of blood loss was determined by measurement of the hemoglobin content of aliquots of blood collected in saline after tail transection as compared with known volumes of blood from the same mouse diluted in the same amount of saline.

Human recombinant Gas6 and Axl extracellular domain. Human recombinant Gas6 was produced in a human embryonic kidney cell line (HEK293) stably transfected with the $\mathrm{pSecTag} 2 /$ Hygro expression vector (Invitrogen Corp.) encoding the human Gas 6 cDNA. Human recombinant Gas6 was purified from conditioned medium using a modification of a calcium affinity method used for proteins containing $\gamma$-carboxy-glutamic acid residues (47, 48). The cDNA encoding a 415-AA mature human Axl extracellular domain (hAxl-EC) was cloned from a human kidney cDNA library (Stratagene). Splice overlap extension was used to fuse the cDNA downstream of the secretion signal of the pSecTag2/Hygro vector (Invitrogen Corp.), followed by in-frame sequence coding for the human IgG-Fcy (R\&D Systems Inc.). The resulting expression vector drives expression and secretion of a hAxl-EC-Fc fusion under the control of the CMV promoter. The plasmid pSecTag2/Hygro-hAxl-EC-Fc was stably transfected in HEK293 cells. The hAxl-EC-Fc was purified on protein A-Sepharose.

Thrombosis models. Mice were anesthetized by i.p. injection of a mixture of ketamine $(80 \mathrm{mg} / \mathrm{kg})$ and xylazine $(16 \mathrm{mg} / \mathrm{kg})$. Thrombus formation due to stasis was induced by injection of tissue thromboplastin (1 vol Innovin/49 vol saline; Innovin was from Dade Behring Inc.) into the dorsal vein of the penis $(5 \mathrm{ml} / \mathrm{kg})$, followed immediately by tightening of 1 suture in the inferior vena cava just below the left renal vein for 15 minutes. Thrombosis was quantified by weighing of the thrombus (49). In mice anesthetized by i.p. injection of sodium pentobarbital $(60 \mathrm{mg} / \mathrm{kg})$, thromboembolism was induced by injection of a mixture of collagen $(0.5 \mathrm{mg} / \mathrm{kg}$, equine collagen; Hormon Chemie) and epinephrine (60 $\mu \mathrm{g} / \mathrm{kg})$ into the jugular vein (30). When indicated, mice received $10 \mu \mathrm{g}$ hAxl-EC-Fc.

Platelet aggregation. Platelet aggregation was performed as described in ref. 7. Briefly, whole blood, drawn from anesthetized mice from the inferior vena cava into $3.13 \%$ citrate ( 1 vol anticoagulant $/ 9$ vol blood), was centrifuged at $100 \mathrm{~g}$ (10 minutes) to obtain PRP and additionally at 2,000 $\mathrm{g}(10$ minutes) to obtain platelet-poor plasma (PPP). PRP and PPP were pooled from 4-6 mice. To prepare washed platelets, apyrase was added to PRP (final concentration, $1 \mathrm{IU} / \mathrm{ml}$ ), and platelets were incubated for $10 \mathrm{~min}$ utes at $37^{\circ} \mathrm{C}$, washed by addition of $2 \mathrm{vol}$ acid-citrate-dextrose solution ( $22 \mathrm{~g}$ trisodium citrate dihydrate, $8 \mathrm{~g}$ citric acid monohydrate, and $25 \mathrm{~g}$ glucose dextrose in 1 liter of $\mathrm{H}_{2} \mathrm{O}$ ), and centrifuged at 2,000 $\mathrm{g}$ (10 minutes). The platelet pellet was resuspended in Tyrode's buffer ( $\mathrm{pH}$ 7.3) containing $137 \mathrm{mM} \mathrm{NaCl}, 2.7 \mathrm{mM} \mathrm{KCl}, 12 \mathrm{mM} \mathrm{NaHCO}_{3}, 0.4 \mathrm{mM} \mathrm{NaH}_{2} \mathrm{PO}_{4}, 5 \mathrm{mM}$ HEPES, and $0.1 \% \mathrm{BSA} . \mathrm{CaCl}_{2}(2 \mathrm{mM}$ final $)$ and $\mathrm{MgCl}_{2}$ (1 $\mathrm{mM}$ final $)$ were added immediately before platelet stimulation. Platelet aggregation was 
measured turbidimetrically using an optical Platelet Aggregation Profiler (model PAP-4; Bio/Data Corp.). When indicated, WT washed platelets were preincubated with hAxl-EC-Fc before stimulation with ADP (1 minute).

Clot retraction. PRP was diluted with PPP to bring the platelet count to 100 $\mathrm{G} / \mathrm{l}$ and put into an aggregation cuvette. Thrombin was added at a final concentration of $10 \mathrm{IU} / \mathrm{ml}$. The aggregation cuvette was then incubated at $37^{\circ} \mathrm{C}$ in the aggregometer for 2 hours without stirring, while the clot retraction was monitored every 15 minutes (N. Prévost, unpublished observations).

Fibrinogen binding. Washed platelets $\left(10^{8} / \mathrm{ml}\right.$ in final volume) were incubated simultaneously with a mixture of PBS (negative control) or ADP (1.25-20 $\mu \mathrm{M}$ in final volume), Oregon Green 488-conjugated fibrinogen $(150 \mu \mathrm{g} / \mathrm{ml}$ in final volume; Invitrogen Corp.), and Tyrode's buffer containing $0.1 \%$ BSA in a final volume of $200 \mu \mathrm{l}$. After 10 minutes at $37^{\circ} \mathrm{C}$ under stirring conditions, samples were fixed by the addition of paraformaldehyde ( $1 \%$ in final volume). Platelets were then resuspended in $500 \mu \mathrm{l}$ PBS containing $0.2 \%$ BSA, and samples were analyzed by flow cytometry using a FACScan instrument (BD Biosciences) and CellQuest software (BD Biosciences).

Platelet secretion. Dense-granule secretion, investigated by platelet ATP release in response to collagen, was monitored in PRP by addition of firefly luciferase and luciferin and comparison of the luminescence generated by platelet ATP release with that generated by an ATP standard (CHRONOLUME; Chrono-Log Corp.), as reported previously (7). To measure $\alpha$ granule secretion, washed platelets $\left(10^{8} / \mathrm{ml}\right)$ were incubated with ADP at various concentrations for 10 minutes at $37^{\circ} \mathrm{C}$ under stirring conditions and subsequently labeled with FITC-conjugated anti-P-selectin antibody (BD Biosciences - Pharmingen) and analyzed by flow cytometry using a FACScan instrument and CellQuest software, as described previously (7).

Adhesion to immobilized fibrinogen. Adhesion to immobilized fibrinogen was quantified as described previously (50). Human fibrinogen (Sigma-Aldrich) in PBS ( $\mathrm{pH}$ 8.0) was plated onto microtiter plates at concentrations ranging from $1 \mathrm{ng}$ to $2 \mu \mathrm{g}$ per well and incubated overnight at $4^{\circ} \mathrm{C}$. Plates were washed twice with PBS ( $\mathrm{pH} 7.4$ ) and blocked for 2 hours at room temperature with 20 $\mathrm{mg} / \mathrm{ml} \mathrm{BSA}$ in PBS. Fifty microliters of washed platelets $\left(6 \times 10^{6}\right)$ in Tyrode's buffer containing $0.1 \%$ BSA was added per well. After 1 hour of incubation, nonadherent platelets were removed, and the wells were washed twice with $150 \mu \mathrm{l}$ Tyrode's buffer supplemented with $1 \mathrm{mM} \mathrm{MgCl}_{2}$. One hundred fifty microliters of pNpp buffer (0.1 M citrate [pH 5.4], 0.1\% Triton X-100, 5 mM para-nitrophenylphosphate) was added for 1 hour at room temperature. Then, $100 \mu \mathrm{l}$ of $2-\mathrm{M} \mathrm{NaOH}$ was added, and adherent platelets were quantified in a microplate reader at $405 \mathrm{~nm}$. The percentage of platelets adhering was determined by calculation of the ratio of bound to maximal signal at 405 $\mathrm{nm}$, where maximal reading was obtained from a microtiter well containing $6 \times 10^{6}$ platelets that was not subjected to washing procedures.

Rhodamine-phalloidin staining. A Lab-Tek chamber slide (Nalge Nunc International) was coated with $100 \mu \mathrm{g} / \mathrm{ml}$ fibrinogen. Washed platelets $\left(6 \times 10^{6}\right)$ in Tyrode's buffer supplemented with $\mathrm{CaCl}_{2}$ and $\mathrm{MgCl}_{2}$ were added to each well of the chamber slide for $15-60$ minutes at $37^{\circ} \mathrm{C}$. Nonadherent platelets were washed away, and adherent cells were fixed in $1 \%$ paraformaldehyde in PBS for 15 minutes at room temperature. After 3 washes with PBS, excess aldehyde was quenched with $10 \mathrm{mM}$ ethanolamine in PBS (or 0.1 M glycine in PBS) for 5 minutes. Platelets were permeabilized in 0.1\% Triton X-100 in PBS for 1 minute and incubated in rhodamine-phalloidin (Sigma-Aldrich) diluted 1:100 in PBS for 15 minutes. The slide was removed from the chamber and then washed 3 times in PBS. Slides were then mounted in VECTASHIELD (Vector Laboratories Inc.). Platelet spreading was analyzed with an Axiophot microscope equipped with an AxioCam camera (Carl Zeiss AG).

Platelet-spreading analysis by video microscopy. Observation chambers coated with human fibrinogen in PBS ( $\mathrm{pH} 8.0)(2 \mathrm{mg} / \mathrm{ml})$ were washed twice with PBS ( $\mathrm{pH} 7.4$ ) and blocked for 2 hours at room temperature with $20 \mathrm{mg} / \mathrm{ml}$ BSA in PBS. Then, washed platelets resuspended in Tyrode's buffer $\left(10^{5}\right)$ were dropped into the chambers and observed with an Axiovert $100 \mathrm{TV}$ inverted microscope (Carl Zeiss AG), equipped with a heated stage $\left(37^{\circ} \mathrm{C}\right)$ and a digital charged-coupled device camera (C4742-95-10; Hamamatsu Photonics). Platelet spreading was recorded with Openlab 3.0.6 software (Improvision) with frame intervals of 15-30 seconds.

Immunoprecipitation and Western blotting. For immunoprecipitation, washed platelets were lysed in the presence of the following protease inhibitors: $1 \mu \mathrm{M} \mathrm{NaVO}_{4}, 1 \mathrm{mM} \mathrm{NaF}$, and complete inhibitors (Roche Diagnostics Corp.). Insoluble materials were removed by centrifugation for 10 minutes at $4{ }^{\circ} \mathrm{C}$. The resulting supernatants were immunoprecipitated with monoclonal anti-phosphotyrosine-agarose (clone PT-66) beads (Sigma-Aldrich). For dose-response and time-course experiments, stirred washed platelets $\left(4 \times 10^{8}\right.$ platelets in $100 \mu 1$ Tyrode's buffer $)$ were stimulated with human recombinant Gas 6 or thrombin at $37^{\circ} \mathrm{C}$. The reaction was stopped by the addition of SDS sample buffer. Sample aliquots were loaded on SDS-PAGE $(10 \%)$ and subjected to Western blotting using 1 of the following antibodies: anti-Rse (also called Tyro3), anti-Axl, anti-Mer, anti-PI3K p85 $\alpha$, anti- $\beta_{3}$ integrin (Santa Cruz Biotechnology Inc.), the PhosphoPlus Akt (Ser473) antibody (Cell Signaling Technology Inc.), or anti- $\beta_{3}$ integrin [ $\left.\mathrm{pY}^{773}\right]$ phosphospecific antibody (Biosource International Inc.). The data are representative of 3-4 independent experiments using PRP pooled from $6 \mathrm{WT}$, Tyro3 $^{-/-}, \mathrm{Axl}^{-/}$, or $\mathrm{Mer}^{-/-}$mice.

Detection of $\beta_{3}$ integrin on platelet surface by flow cytometry. Washed platelets $\left(10^{8} / \mathrm{ml}\right)$ were incubated with PE-conjugated anti- $\beta_{3}$ integrin antibody (BD Biosciences - Pharmingen) and analyzed by flow cytometry using a FACScan instrument and CellQuest software.

Gas6 binding. Washed platelets $\left(10^{8} / \mathrm{ml}\right.$ in final volume) were incubated simultaneously with PBS (negative control) or myc-tagged recombinant Gas6 $(5 \mu \mathrm{g} / \mathrm{ml}$ in final volume) and FITC-conjugated anti-myc-tag antibody (Abcam Ltd.) in Tyrode's buffer containing $0.1 \%$ BSA in a final volume of $200 \mu \mathrm{l}$ at $37^{\circ} \mathrm{C}$ for 10 minutes under stirring conditions. The reaction was stopped by the addition of paraformaldehyde ( $1 \%$ in final volume), and platelets were resuspended in $500 \mu \mathrm{l}$ PBS containing $0.2 \%$ BSA and analyzed by flow cytometry using a FACScan instrument and CellQuest software.

Detection of Gas6-R on platelet surface by flow cytometry. Resting washed platelets $\left(10^{8} / \mathrm{ml}\right.$ in final volume) or washed platelets activated by the PAR4-activating peptide AYPGKF at $0.25 \mathrm{mM}$ for 10 minutes at $37^{\circ} \mathrm{C}$ under stirring conditions were incubated with an anti-Tyro3, an anti-Axl, or an anti-Mer antibody (R\&D Systems Inc.). Tyro3, Axl, or Mer was subsequently detected on platelets by a FITC-conjugated rabbit anti-rat antibody and analyzed by flow cytometry using a FACScan instrument and CellQuest software.

\section{Acknowledgments}

We thank Bart Hermans, Solange Charvier, and W. Yen Man for technical assistance, Nicolas Prévost for the clot retraction protocol, Shozo Izui for the antiplatelet $\mathrm{mAb} \mathrm{CV}-5 \mathrm{H} 7$, and Margaret Rand for critical reading of the manuscript. This work was supported by the Wilsdorf Foundation, the Dinu Lipatti-Dr Henri Dubois-Ferrière Foundation, The Sir Jules Thorn Charitable Trust, the Roche Research Foundation, and the Swiss National Foundation for Scientific Research grants 3232-066350.01 (Swiss Clinicians Opting for Research) and 3200-066351.01.

Received for publication May 5, 2004, and accepted in revised form November 23, 2004.

Address correspondence to: Anne Angelillo-Scherrer, Division of Angiology and Hemostasis, University Medical Center, 1 rue MichelServet, CH-1211 Geneva 14, Switzerland. Phone: 41-22-379-55-67; Fax: 41-22-372-92-99; E-mail: Anne.Angelillo@medecine.unige.ch. 
1. Prevost, N., Woulfe, D., Tognolini, M., and Brass, L.F. 2003. Contact-dependent signaling during the late events of platelet activation. J. Thromb. Haemost. 1:1613-1627.

2. Law, D.A., et al. 1999. Integrin cytoplasmic tyrosine motif is required for outside-in alphallbbeta3 signalling and platelet function. Nature. 401:808-811.

3. Phillips, D.R., Prasad, K.S., Manganello, J., Bao, M., and Nannizzi-Alaimo, L. 2001. Integrin tyrosine phosphorylation in platelet signaling. Curr. Opin. Cell Biol. 13:546-554

4. Pasquet, J.M., Noury, M., and Nurden, A.T. 2002 Evidence that the platelet integrin alphaIIb beta3 is regulated by the integrin-linked kinase, ILK, in a PI3-kinase dependent pathway. Thromb. Haemost. 88:115-122.

5. Prevost, N., Woulfe, D., Tanaka, T., and Brass, L.F. 2002. Interactions between Eph kinases and ephrins provide a mechanism to support platelet aggregation once cell-to-cell contact has occurred. Proc. Natl. Acad. Sci. U. S. A. 99:9219-9224.

6. Prasad, K.S., et al. 2003. Soluble CD40 ligand induces beta3 integrin tyrosine phosphorylation and triggers platelet activation by outside-in signaling. Proc. Natl. Acad. Sci. U. S. A. 100:12367-12371.

7. Angelillo-Scherrer, A., et al. 2001. Deficiency or inhibition of Gas 6 causes platelet dysfunction and protects mice against thrombosis. Nat. Med. 7:215-221.

8. Nagata, K., et al. 1996. Identification of the product of growth arrest-specific gene 6 as a common ligand for Axl, Sky, and Mer receptor tyrosine kinases. J. Biol. Chem. 271:30022-30027.

9. Varnum, B.C., et al. 1995. Axl receptor tyrosine kinase stimulated by the vitamin K-dependent protein encoded by growth-arrest-specific gene 6 . Nature. 373:623-626.

10. Sasaki, T., et al. 2002. Crystal structure of a C-terminal fragment of growth arrest-specific protein Gas 6 Receptor tyrosine kinase activation by laminin G-like domains. J. Biol. Chem. 277:44164-44170.

11. O'Bryan, J.P., et al. 1991. axl, a transforming gene isolated from primary human myeloid leukemia cells, encodes a novel receptor tyrosine kinase. Mol. Cell. Biol. 11:5016-5031.

12. Rescigno, J., Mansukhani, A., and Basilico, C. 1991. A putative receptor tyrosine kinase with unique structural topology. Oncogene. 6:1909-1913.

13. Lai, C., Gore, M., and Lemke, G. 1994. Structure, expression, and activity of Tyro 3 , a neural adhesion-related receptor tyrosine kinase. Oncogene. 9:2567-2578

14. Mark, M.R., et al. 1994. rse, a novel receptor-type tyrosine kinase with homology to Axl/Ufo, is expressed at high levels in the brain. J. Biol. Chem. 269:10720-10728.

15. Graham, D.K., Dawson, T.L., Mullaney, D.L., Snodgrass, H.R., and Earp, H.S. 1994. Cloning and mRNA expression analysis of a novel human protooncogene, c-mer. Cell Growth Differ. 5:647-657.

16. Mark, M.R., Chen, J., Hammonds, R.G., Sadick, M., and Godowsk, P.J. 1996. Characterization of Gas6 a member of the superfamily of $G$ domain-containing proteins, as a ligand for Rse and Axl. J. Biol. Chem. 271:9785-9789.
17. Chen, J., Carey, K., and Godowski, P.J. 1997. Identification of Gas6 as a ligand for Mer, a neural cell adhesion molecule related receptor tyrosine kinase implicated in cellular transformation. Oncogene. 14:2033-2039.

18. Goruppi, S., Ruaro, E., and Schneider, C. 1996. Gas6, the ligand of Axl tyrosine kinase receptor, has mitogenic and survival activities for serum starved NIH3T3 fibroblasts. Oncogene. 12:471-480.

19. Goruppi, S., Ruaro, E., Varnum, B., and Schneider, C. 1999. Gas6-mediated survival in NIH3T3 cells activates stress signalling cascade and is independent of Ras. Oncogene. 18:4224-4236.

20. Demarchi, F., Verardo, R., Varnum, B., Brancolini, C., and Schneider, C. 2001. Gas6 anti-apoptotic signaling requires NF-kappa B activation. J. Biol. Chem. 276:31738-31744.

21. Lu, Q., et al. 1999. Tyro-3 family receptors are essential regulators of mammalian spermatogenesis. Nature. 398:723-728.

22. Herbert, J.M., Bernat, A., and Maffrand, J.P. 1992. Importance of platelets in experimental venous thrombosis in the rat. Blood. 80:2281-2286.

23. Kawasaki, T., Dewerchin, M., Lijnen, H.R., Vermylen, J., and Hoylaerts, M.F. 2000. Vascular release of plasminogen activator inhibitor- 1 impairs fibrinolysis during acute arterial thrombosis in mice. Blood. 96:153-160.

24. Kawasaki, T., et al. 2001. Mouse carotid artery ligation induces platelet-leukocyte-dependent luminal fibrin, required for neointima development. Circ. Res. 88:159-166.

25. Piguet, P.F., et al. 1993. An effector role for platelets in systemic and local lipopolysaccharide-induced toxicity in mice, mediated by a CD11a- and CD54dependent interaction with endothelium. Infect. Immun. 61:4182-4187.

26. Sambrano, G.R., Weiss, E.J., Zheng, Y.W., Huang, W., and Coughlin, S.R. 2001. Role of thrombin signalling in platelets in haemostasis and thrombosis. Nature. 413:74-78.

27. Shattil, S.J., Kashiwagi, H., and Pampori, N. 1998. Integrin signaling: the platelet paradigm. Blood. 91:2645-2657.

28. Heiring, C., Dahlback, B., and Muller, Y.A. 2003. Ligand recognition and homophilic interactions in Tyro3: structural insights into the Axl/Tyro3 receptor tyrosine kinase family. J. Biol. Chem. 279:6952-6958.

29. Payrastre, B., et al. 2000. The integrin alpha IIb/ beta 3 in human platelet signal transduction. Biochem. Pharmacol. 60:1069-1074.

30. DiMinno, G., and Silver, M.J. 1983. Mouse antithrombotic assay: a simple method for the evaluation of antithrombotic agents in vivo. Potentiation of antithrombotic activity by ethyl alcohol. J. Pharmacol. Exp. Ther. 225:57-60.

31. Konishi, A., Aizawa, T., Mohan, A., Korshunov, V.A. and Berk, B.C. 2004. Hydrogen peroxide activates the Gas6-Axl pathway in vascular smooth muscle cells. J. Biol. Chem. 279:28766-28770.

32. Hall, M.O., Agnew, B.J., Abrams, T.A., and Burgess, B.L. 2003. The phagocytosis of os is mediated by the PI3-kinase linked tyrosine kinase receptor, mer, and is stimulated by GAS6. Adv. Exp. Med. Biol.
533:331-336

33. Lu, Q., and Lemke, G. 2001. Homeostatic regulation of the immune system by receptor tyrosine kinases of the Tyro 3 family. Science. 293:306-311.

34. Burgering, B.M., and Coffer, P.J. 1995. Protein kinase $\mathrm{B}$ (c-Akt) in phosphatidylinositol-3-OH kinase signal transduction. Nature. 376:599-602.

35. Kovacsovics, T.J., et al. 1995. Phosphoinositide 3-kinase inhibition spares actin assembly in activating platelets but reverses platelet aggregation. J. Biol. Chem. 270:11358-11366.

36. Trumel, C., et al. 1999. A key role of adenosine diphosphate in the irreversible platelet aggregation induced by the PAR1-activating peptide through the late activation of phosphoinositide 3-kinase. Blood. 94:4156-4165.

37. Hodivala-Dilke, K.M., et al. 1999. 33 -integrin-deficient mice are a model for Glanzmann thrombasthenia showing placental defects and reduced survival. J. Clin. Invest. 103:229-238.

38. Smyth, S.S., Reis, E.D., Vaananen, H., Zhang, W., and Coller, B.S. 2001. Variable protection of beta 3integrin-deficient mice from thrombosis initiated by different mechanisms. Blood. 98:1055-1062.

39. Fabre, J.E., et al. 1999. Decreased platelet aggregation, increased bleeding time and resistance to thromboembolism in P2Y1-deficient mice. Nat. Med. 5:1199-1202.

40. Leon, C., et al. 1999. Defective platelet aggregation and increased resistance to thrombosis in purinergic P2Y(1) receptor-null mice. J. Clin. Invest. 104:1731-1737.

41. Andre, P., et al. 2003. P2Y12 regulates platelet adhesion/activation, thrombus growth, and thrombus stability in injured arteries. J. Clin. Invest. 112:398-406

42. Offermanns, S., Toombs, C.F., Hu, Y.H., and Simon, M.I. 1997. Defective platelet activation in G alpha(q)-deficient mice. Nature. 389:183-186.

43. Weiss, E.J., Hamilton, J.R., Lease, K.E., and Coughlin, S.R. 2002. Protection against thrombosis in mice lacking PAR3. Blood. 100:3240-3244.

44. Andre, P., et al. 2002. CD40L stabilizes arterial thrombi by a beta3 integrin-dependent mechanism. Nat. Med. 8:247-252.

45. Munoz, X., et al. 2004. Human vitamin K-dependent GAS6: gene structure, allelic variation, and association with stroke. Hum. Mutat. 23:506-512.

46. Nurden, A.T. 1996. New thoughts on strategies for modulating platelet function through the inhibition of surface receptors. Haemostasis. 26(Suppl. 4):78-88.

47. Grinnell, B.W., et al. 1990. Gamma-carboxylated isoforms of recombinant human protein $\mathrm{S}$ with different biologic properties. Blood. 76:2546-2554.

48. Yan, S.B. 1996. Review of conformation-specific affinity purification methods for plasma vitamin K-dependent proteins. J. Mol. Recognit. 9:211-218.

49. Vogel, G.M., Meuleman, D.G., Bourgondien, F.G., and Hobbelen, P.M. 1989. Comparison of two experimental thrombosis models in rats effects of four glycosaminoglycans. Thromb. Res. 54:399-410.

50. Law, D.A., et al. 1999. Genetic and pharmacological analyses of Syk function in alphaIIbbeta3 signaling in platelets. Blood. 93:2645-2652. 